\title{
Hubungan antara Motivasi dan Penerimaan dengan Pencapaian Akademik Pelajar dalam Pelajaran Menggunakan M-pembelajaran di Kolej Vokasional
}

\author{
Roghdaryanti Hashim ${ }^{1 *}$, Maizatul Hayati Mohamad Yatim ${ }^{1}$ \\ ${ }^{1}$ Fakulti Seni, Komputeran dan Industri Kreatif, Universiti Pendidikan Sultan Idris.
}

Article History

Received:

21.09.2019

Revised:

27.10.2019

Accepted:

21.11.2019

*Corresponding Author:

Roghdaryanti Hashim

Email:

cikguyantihashim@gmail.com
Abstrak: Kajian ini bertujuan untuk menentukan hubungan antara motivasi dan penerimaan dengan pencapaian akademik pelajar dalam pembelajaran Penyelenggaraan Pencegahan Komputer menggunakan m-learning di kolejkolej kejuruan. Dalam kajian ini, teori motivasi Teori Penentuan Diri telah diintegrasikan dengan model penerimaan UTAUT. Kajian ini merupakan kajian kuantitatif mengenai reka bentuk relasi, yang menggunakan teknik pensampelan mudah rawak kepada 70 responden dari 85 populasi yang mengambil kursus Penyelenggaraan Pencegahan Komputer di empat kolej vokasional yang terletak di Kuala Lumpur dan Selangor. Keputusan menunjukkan bahawa semua pembolehubah bebas mempunyai hubungan yang signifikan dengan pencapaian akademik pelajar, tetapi hanya motivasi pengajaran, keseronokan dan niat tingkah laku adalah faktor yang mempengaruhi pencapaian akademik pelajar. Motivasi pengajaran lebih berpengaruh kepada pelajar daripada motivasi ekstrinsik dan tahap penerimaan pelajar dalam m-learning dalam aktiviti pembelajaran adalah tinggi.

Kata Kunci: m-Pelajaran, Motivasi, Penerimaan, Pencapaian Akademik.

The Relationship between Motivation and Acceptance with Student Academic Achievement in Learning Using M-learning in Vocational College

Abstract: This study aimed to determine the relationship between motivation and acceptance with students' academic achievement in Computer Preventive Maintenance learning using m-learning in vocational colleges. In this study, the motivational theory of Self-Determination Theory has been integrated with the UTAUT acceptance model. This study was a quantitative study of relational design, which applied simple random sampling techniques to 70 respondents from 85 populations who took Computer Preventive Maintenance courses at four vocational colleges located in Kuala Lumpur and Selangor. The results showed that all of the independent variables have a significant relationship with students' academic achievement, but only instructional motivation, enjoyment and behavioral intention are factors that influence student academic achievement. Instructional motivation is more influential to students than extrinsic motivation and the level of student acceptance of $\mathrm{m}$ learning in learning activities is high.

Keywords: m-Learning, Motivation, Acceptance, Academic Achievement. 


\section{Pendahuluan}

Hasrat Kementerian Pendidikan Malaysia untuk mentranformasikan sekolah menengah vokasional menjadi kolej vokasional melalui Pelan Tranformasi Pendidikan Vokasional adalah bertujuan untuk menangani cabaran permintaan sumber tenaga mahir yang semakin berkurangan di Malaysia [1]. Persekitaran pembelajaran yang baharu di kolej vokasional telah mewujudkan beberapa faktor penghalang yang menyumbang ke arah kesulitan penggunaan ICT dalam proses pengajaran dan pembelajaran. Antara faktor penghalang yang utama adalah kekerapan tenaga pengajar keluar menjalankan tugas rasmi seperti menghadiri kursus peningkatan kemahiran dan mesyuarat penambahbaikan program adalah tinggi, peralatan fizikal tidak mencukupi dan tidak mengikuti perkembangan teknologi terkini, bahan pengajaran dan pembelajaran yang tidak selaras di antara semua kolej vokasional dan kebanyakkannya adalah berbentuk softcopy, e-book dan rujukan laman sesawang yang mana perlu dibuat salinan yang banyak untuk setiap pelajar, dan akhir sekali, kurikulum yang dibangunkan sering berubah dan tidak sesuai dengan kaedah pengajaran dan pembelajaran semasa iaitu kaedah konvensional pembelajaran bersemuka.

Salah satu agenda penting Pelan Pembangunan Pendidikan Malaysia (PPPM) 2013 - 2025 untuk mentranformasi sistem pendidikan negara adalah anjakan ke tujuh yang memfokuskan terhadap pemanfaatan ICT bagi meningkatkan kualiti pembelajaran di Malaysia. Anjakan ini juga memaksimumkan penggunaan ICT bagi pembelajaran jarak jauh dan pembelajaran secara kendiri untuk memperluaskan akses kepada pengajaran berkualiti tinggi tanpa mengira lokasi, masa atau tahap kemahiran pelajar.

Penggunaan peralatan mudah alih telah berkembang secara meluas di seluruh dunia disebabkan oleh kebolehan dan kemampuannya berfungsi dalam pelbagai cara dan penggunaannya telah menembusi bidang pendidikan. Pelajar dan tenaga pengajar di seluruh dunia semakin giat menggunakannya untuk mengakses maklumat, menyelaras urusan pentadbiran dan mempelbagaikan kaedah yang baharu dan inovatif dalam aktiviti pembelajaran [2]. Apabila trend teknologi peralatan mudah alih telah mula digunakan dalam pendidikan, corak pendidikan sedia ada e-pembelajaran telah mula berkembang dengan mewujudkan satu kaedah pembelajaran yang baharu iaitu m-pembelajaran.

M-pembelajaran adalah penggunaan teknologi komunikasi mudah alih tanpa wayar dalam institusi pendidikan tanpa mengira lokasi dan masa [3], [4], [5]. Jadi, dengan hasrat untuk melahirkan modal insan yang kreatif, inovatif dan berkemahiran tinggi, m-pembelajaran adalah kaedah pengajaran dan pembelajaran yang digunakan dalam kajian ini untuk mencapai objektif bagi menentukan hubungan antara motivasi ekstrinsik, motivasi instrinsik, jangkaan prestasi, jangkaan usaha, pengaruh sosial, keadaan kemudahan, keseronokan dan niat tingkahlaku dengan pencapaian akademik pelajar dalam pembelajaran Computer Preventive Maintenance menggunakan m-pembelajaran, menganalisis faktor ramalan pencapaian akademik pelajar dalam pembelajaran Computer Preventive Maintenance menggunakan m-pembelajaran daripada motivasi ekstrinsik, motivasi instrinsik, jangkaan prestasi, jangkaan usaha, pengaruh sosial, keadaan kemudahan, keseronokan dan niat tingkahlaku, dan menganalisis faktor ramalan bahagian varian pencapaian akademik

Pelajar dalam pembelajaran Computer Preventive Maintenance.

\section{Kerangka Konseptual Kajian}

Kerangka konseptual kajian dibentangkan pada Rajah 1.

\section{Metodologi Kajian}

\subsection{Rekabentuk Kajian}

Rekabentuk kajian adalah penyelidikan kuantitatif berbentuk statistik deskriptif dengan rekabentuk hubungan (korelasi). Analisis yang digunakan dalam kajian ini adalah analisis statistik deskriptif, analisis kesahan dan kebolehpercayaan instrumen, analisis ujian korelasi Pearson (Bivariate), analisis pekali regresi berganda, analisis tahap pengaruh motivasi pelajar dan tahap penerimaan pelajar terhadap teknologi baharu.

\subsection{Populasi dan Sampel}

Kaedah persampelan bertujuan digunakan untuk menetapkan lokasi kajian kumpulan populasi iaitu empat buah kolej vokasional yang menawarkan program Teknologi Sistem Komputer dan Rangkaian di Kuala Lumpur dan Selangor. Manakala kaedah persampelan rawak mudah digunakan untuk memilih 70 orang responden daripada 85 orang pelajar semester tiga Sijil Vokasional 
Malaysia (SVM) program Teknologi Sistem Komputer dan Rangkaian yang mengikuti kursus Computer Preventive Maintenance.

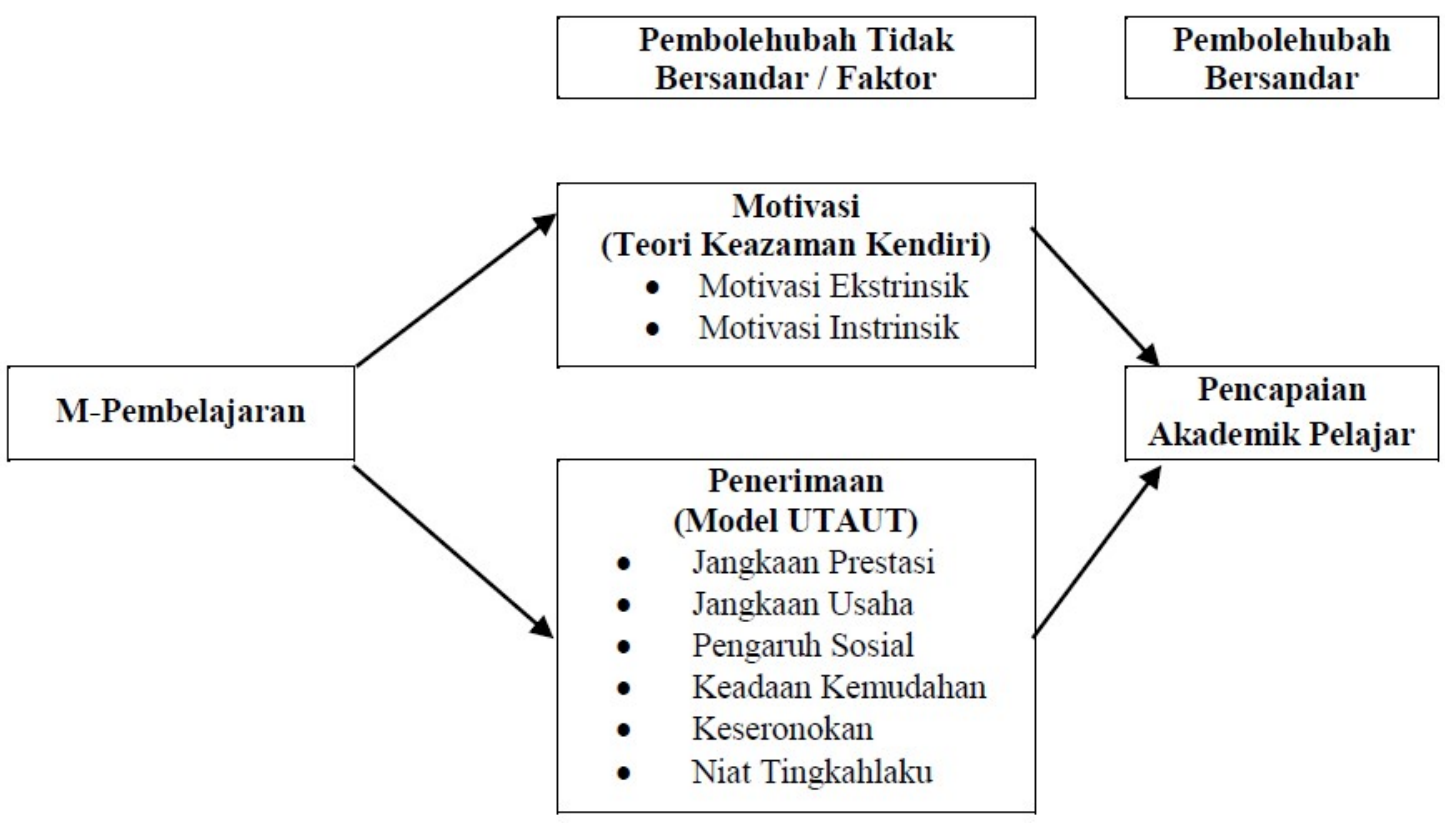

Rajah 1. Kerangka Konseptual Kajian

\subsection{Instrumen}

Instrumen soal selidik telah digunakan dalam kajian ini. Set instrumen ini mempunyai tiga bahagian iaitu Bahagian A (Maklumat Demografi), Bahagian B (Tahap Motivasi Pelajar) dan Bahagian B (Tahap Penerimaan Pelajar). Kedua-dua instrumen ini diadaptasi daripada pengkaji yang terdahulu dan digabungkan dalam satu instrumen.

\subsection{Kajian Rintis}

Kajian rintis telah dilaksanakan untuk menguji kesahan dan kebolehpercayaan instrumen, serta mengenalpasti masalah dan kekeliruan dalam instrumen. Hasil daripada analisis kesahan instrumen (bahasa dan kandungan), didapati bahawa peratus persetujuan panel pakar adalah $91 \%$ dan ini menunjukkan bahawa item-item dalam instrumen ini adalah sesuai untuk dikekalkan dengan sedikit pemurnian. Jika mendapat lebih daripada $80 \%$ persetujuan pakar, item adalah sesuai dan dikekalkan. Item perlu diubahsuai dan dimurnikan berdasarkan komen dan cadangan kumpulan panel pakar jika mendapat $60 \%$ hingga $80 \%$ persetujuan pakar, manakala akan ada item yang disingkirkan jika mendapat kurang daripada $60 \%$ persetujuan pakar [6], [7].

Manakala hasil analisis kebolehpercayaan menunjukkan bahawa nilai Cronbach Alpha bagi keseluruhan item adalah .98 dan nilai ini menyokong dapatan bahawa instrumen ini mempunyai nilai kebolehpercayaan yang amat tinggi dan sesuai digunakan dalam kajian yang sebenar.

\section{Dapatan Kajian}

\subsection{Analisis Kebolehpercayaan Instrumen}

Hasil analisis menunjukkan tiada item yang digugurkan dan nilai Cronbach Alpha bagi keseluruhan item adalah .96 dan ini mengesahkan bahawa instrumen ini mempunyai nilai kebolehpercayaan yang amat tinggi. 


\subsection{Analisis Statistik Deskriptif}

Hasil analisis menunjukkan bahawa semua pembolehubah mempunyai normaliti dan nilai min serta sisihan piawai adalah seperti yang ditunjukkan dalam Jadual 1.

Jadual 1. Analisis Statistik Deskriptif

\begin{tabular}{|l|c|c|}
\hline \multicolumn{1}{|c|}{ Pembolehubah } & $\begin{array}{c}\text { Min } \\
(\mathbf{M})\end{array}$ & $\begin{array}{c}\text { Sisihan Piawai } \\
\text { (SP) }\end{array}$ \\
\hline Pencapaian Pelajar & 88.59 & 4.26 \\
\hline Motivasi Ekstrinsik & 31.97 & 3.04 \\
\hline Motivasi Instrinsik & 37.99 & 1.84 \\
\hline Jangkaan Prestasi & 18.60 & 1.46 \\
\hline Jangkaan Usaha & 24.06 & 1.13 \\
\hline Pengaruh Sosial & 9.54 & .65 \\
\hline Keadaan Kemudahan & 47.70 & 3.05 \\
\hline Keseronokan & 27.80 & 2.27 \\
\hline Niat Tingkahlaku & 14.53 & .97 \\
\hline
\end{tabular}

\subsection{Analisis Ujian Korelasi Pearson}

Hasil analisis menunjukkan bahawa kesemua pembolehubah tidak bersandar mempunyai hubungan yang signifikan dengan pencapaian akademik pelajar. Hasil analisis ujian korelasi Pearson (Bivariate) dibentangkan pada Jadual 2.

Jadual 2. Analisis Ujian Korelasi Pearson (Bivariate)

\begin{tabular}{|l|c|}
\hline \multicolumn{1}{|c|}{ Hubungan } & $\begin{array}{c}\text { Pencapaian } \\
\text { Akademik Pelajar }\end{array}$ \\
\hline Motivasi Ekstrinsik & $.76^{*}$ \\
\hline Motivasi Instrinsik & $.84^{*}$ \\
\hline Jangkaan Prestasi & $.69^{*}$ \\
\hline Jangkaan Usaha & $.56^{*}$ \\
\hline Pengaruh Sosial & $.54^{*}$ \\
\hline Keadaan Kemudahan & $.66^{*}$ \\
\hline Keseronokan & $.81^{*}$ \\
\hline Niat Tingkahlaku & $.73^{*}$ \\
\hline
\end{tabular}

Nota: ${ }^{*} \mathrm{p}<.05$

Jadual 2. menunjukkan bahawa motivasi instrinsik dan keseronokan mempunyai hubungan yang kuat dengan pencapaian akademik pelajar berbanding pembolehubah yang lain.

\subsection{Analisis Pekali Regresi Berganda}

Hasil analisis menunjukkan bahawa secara signifikannya hanya tiga pembolehubah peramal iaitu motivasi instrinsik $(\beta=.34, \mathrm{t}=2.70, \mathrm{p}<.05)$, keseronokan $(\beta=.38, \mathrm{t}=3.46, \mathrm{p}<.05)$ dan niat tingkahlaku $(\beta=.25, \mathrm{t}=2.89, \mathrm{p}<.05)$ adalah merupakan faktor peramal kepada pencapaian akademik pelajar dalam pembelajaran Computer Preventive Maintenance menggunakan m-pembelajaran. Secara keseluruhannya, pembolehubah peramal motivasi instrinsik, keseronokan dan niat tingkahlaku menyumbang sebanyak 77.4 peratus perubahan varians kepada pencapaian akademik pelajar dalam pembelajaran Computer Preventive Maintenance menggunakan m-pembelajaran $[\mathrm{F}(3,66)=75.21$, $\mathrm{p}<.05]$. 


\subsection{Analisis Tahap Pengaruh Motivasi Pelajar}

Hasil analisis menunjukkan bahawa skor purata min bagi motivasi instrinsik adalah 4.75 dan sisihan piawai .43, manakala skor purata min bagi motivasi ekstrinsik adalah 4.57 dan sisihan piawai .50 . ini mengesahkan bahawa motivasi instrinsik adalah lebih mempengaruhi pencapaian akademik pelajar dalam pembelajaran Computer Preventive Maintenance menggunakan m-pembelajaran berbanding motivasi ekstrinsik. Ringkasnya, pelajar tidak mengharapkan sebarang imbuhan setelah melaksanakan sesuatu tugasan tetapi merasa seronok dan puas hati dalam meneroka ilmu baharu dalam aktiviti pembelajaran mereka.

\subsection{Analisis Tahap Penerimaan Pelajar Terhadap Teknologi Baharu}

Hasil analisis menunjukkan bahawa secara keseluruhannya tahap penerimaan pelajar terhadap penggunaan m-pembelajaran dalam aktiviti pembelajaran mereka bagi kesemua konstruk UTAUT iaitu jangkaan prestasi, jangkaan usaha, pengaruh sosial, keadaan kemudahan, keseronokan dan niat tingkahlaku adalah tinggi yang mana nilai skor purata min adalah di antara 4.63 hingga 4.81 . Dapatan ini mengesahkan bahawa pelajar telah bersedia untuk menerima dan menggunakan mpembelajaran dalam aktiviti pembelajaran mereka.

\section{Perbincangan}

Faktor peramal motivasi instrinsik, keseronokan dan niat tingkahlaku dikatakan mempunyai kaitan di antara satu dengan yang lain. Motivasi instrinsik adalah merupakan faktor peramal yang mempengaruhi pencapaian pelajar kerana pelajar mempunyai perasaan minat yang tinggi terhadap apa yang dilakukannya. Pelajar yang mempunyai tahap motivasi instrinsik yang tinggi, tidak mengharapkan sesuatu ganjaran hasil daripada penggunaan m-pembelajaran dalam aktiviti pembelajaran mereka. Ini adalah kerana mereka sendiri telah menunjukkan minat yang sangat mendalam untuk mencapai kepuasan dan keseronokan sendiri. Dorongan dalaman dari diri mereka inilah yang membina motivasi instrinsik, dan pencapaian akademik mereka juga akan meningkat. Seiring dengan motivasi instrinsik, niat tingkahlaku juga adalah hasrat yang tinggi dan mendalam untuk seseorang pelajar itu menggunakan m-pembelajaran dalam aktiviti pembelajaran bagi kursus yang mereka ikuti.

Apabila seseorang pelajar itu mempunyai perasaan minat dan seronok, mereka bersemangat tinggi, maka akan mempunyai hasrat yang tinggi juga untuk menggunakan m-pembelajaran. Dapatan ini menyokong kajian Ali et al. [8], Lee et al. [9] dan Uk Raai et al. [10] yang mendapati bahawa keseronokan mewakili motivasi instrinsik yang mengukur tahap kepercayaan pengguna untuk menggunakan sesuatu teknologi itu demi kepuasan dan keseronokan diri. Motivasi instrinsik memberikan kesan yang positif ke atas penerimaan teknologi dan seterusnya meningkatkan lagi prestasi pencapaian akademik mereka. Justeru itu, ini akan mempengaruhi pencapaian akademik mereka [11], [12]. Menurut Hanim et al. [13] faktor kemahiran guru dalam mengajar berpengaruh terhadap pencapaian akademik seseorang. Kemahiran guru dalam hal ini mengembangkan kreativiti anak melalui penggunaan teknologi. Perpaduan penggunaan teknologi dengan model pembelajaran akan meningkatkan pencapaian akademik pelajar. Penggunaan model pembelajaran berpengaruh terhadap pemahaman konsep pelajar [14]. Faktor guru dalam hal ini termasuk motivasi ekstrinsik.

\section{Kesimpulan}

Motivasi instrinsik lebih mempengaruhi pelajar berbanding motivasi ekstrinsik dan tahap penerimaan pelajar terhadap penggunaan m-pembelajaran dalam aktiviti pembelajaran adalah tinggi

\section{Rujukan}

[1] Buletin Anjakan, "Transformasi Pendidikan Vokasional," Buletin Anjakan, August 2015. [Online]. Available: http://www.padu.edu.my/anjakan. [Accessed: May 2019]

[2] UNESCO Policy Guidelines for Mobile Learning, UNESCO Working Paper Series on Mobile Learning. Fance, 2013. [Online]. Available: https://doi.org/ISBN 978-92-3-001143-7. France.

[3] N. A. Jamilluddin, M. Jasmy, A. Rahman, and N. A. Razali, "Pengadaptasian "E-Learning" Kepada "M- Learning"," in Teknologi Pendidikan, pp. 572-580, 2016. 
[4] A. Althunibat, "Determining the Factors Influencing Student's Intention to Use M-learning," in Jordan Higher Education Computers in Human Behavior, vol. 52, pp. 65-71, 2015. [Online]. Available: https://doi.org/ 10. 1016/ j.chb. 2015.05.046

[5] V. I. Toktarova, A. D. Blagova, A. V. Filatova, and N. V. Kuzmin, "Design and Implementation of Mobile Learning Tools and Resources in the Modern Educational Environment of University," Review of European Studies, vol. 7, no. 8, pp. 318-324, 2015.

[6] M. N. F. Lee and L. T. Wei, "Kesahan dan kebolehpercayaan instrumen penilaian kendiri pembelajaran Geometri Tingkatan Satu," Malaysian Journal of Learning and Instruction, vol. 14, no. 1, pp. 211-265, 2017.

[7] H. M. S. Gani, S. Noor Shah, A. S. Kumar, M. Mastura, and H. K. N. Zaim, "Transformation of Research Instrument Development in Education," US-China Education Review, vol. 4, no. 10, pp. 679-687, 2014.

[8] R. A. Ali, M. Rafie, and M. Arshad, "Perspectives of Students' Behavior towards Mobile Learning (M-learning) in Egypt: an Extension of the UTAUT Model. Engineering, Technology \& Applied Science Research, vol. 6, no. 4, pp. 1108-1113, 2016. [Online]. Available: https://doi.org/10.5281/zenodo.61006. [Accessed: May 2019]

[9] Y. Lee, J. Lee, and Y. Hwang, "Relating Motivation to Information and Communication Technology Acceptance: Self-Determination Theory Perspective," Computers in Human Behavior, vol. 51, pp. 418-428, 2015. [Online]. Available: https://doi.org/10.1016/j.chb.2015. 05.021. [Accessed: May 2019]

[10] U. R. Chen, A. Masek, and M. H. Amiruddin, "Kajian Gaya Pembelajaran dan Motivasi terhadap Pencapaian Pelajar Diploma Kejuruteraan di Politeknik," CiE-TVET 2014, vol. 8, pp. 117-136, 2014.

[11] H. Chung, S. Chen, and M. Kuo, "A Study of EFL College Students' Acceptance of Mobile Learning," Procedia - Social and Behavioral Sciences, vol. 176, pp. 333-339, 2015.

[12] Y. Huang, Empirical Analysis on Factors Impacting Mobile Learning Acceptance in Higher Engineering Education. 2014. [Online]. Available: http://trace.tennessee.edu/utk_graddiss/2751

[13] N. S. Hanim, Jasmine, H. A. Nur, D. Y. Florence, Salina, Nicorsons, Gilbert, and Mohd Razimi, "Pelajar Berkecerdasan Tinggi dalam Kalangan Pelajar Kelas Rancangan Khas," International Jurnal of Humanities, Management and Social Science, vol. 2, no. 1, pp. 1-13.

[14] N. Laili, E. P. Sigid, and A. Fitri, "Pengaruh Model Penemuan Terbimbing Berbantu LKPD terhadap Kemampuan Pemahaman Konsep Matematis Siswa SMPN 6 Depok," International Jurnal of Humanities, Management and Social Science, vol. 2, no. 1, pp. 14-37, 2019. 